\title{
Scientific and practical aspects of extremal situations development in environmental and socio-economic frames of Ukraine and the European Union
}

\author{
Tetiana Tkachenko ${ }^{1}$, Oleksandr Hladkyi $^{1 *}$, Valentyna Zhuchenko ${ }^{1}$, and Vladyslav Bilyk ${ }^{1}$ \\ ${ }^{1}$ Kyiv National University of Trade and Economics, 19, Kyoto str., 02156, Kyiv, Ukraine
}

\begin{abstract}
The theoretic fundamentals of the geography of extremal situations as a new approach for environmental science and socioeconomic investigations are disclosed. The new direction of research named the geography of extreme situations is substantiated. The formation of the extreme operating mode in socio-ecological-economic systems (landscapes) that have a destructive, unbalanced nature and lead to imbalances in their development is explored. The term «geography of extreme situations» is introduced to determine the particular area of geographical knowledge, which studies natural and socio-economic phenomena that have the character of fast imbalance. The methodical approaches to investigation of the extremeness level of the territory via the example of Ukraine and the European Union are shown. In geography this approach was applied only to determine the specific features of the influence of natural conditions on human activity. The indicators of environmental disasters that include the amount of pollutant emissions into the atmosphere, the discharge of contaminated sewage into the natural surface water, the degradation of soil resources, the reduction of the forest fund, the species diversity of flora and fauna are disclosed. The different indices of extremeness such as medical and demographic, socioeconomic, engineering, physical-geographical and others are proposed.
\end{abstract}

\section{Introduction}

The aim of this study is to substantiate a new direction of research named the geography of extreme situations. It examines such features of socio-ecological-economic systems (landscapes) that have a destructive, unbalanced nature and lead to imbalances in their development, the formation of the extreme operating mode. Extreme situations have a high speed of implementation and dissemination. The term «geography of extreme situations» is introduced to determine the particular area of geographical knowledge, which studies natural and social phenomena that have the character of fast imbalance. They are to a great extent a hindrance to the sustainable development of the regions in the natural, economic, social, environmental aspects.

\footnotetext{
${ }^{*}$ Corresponding author: $\underline{\text { o.gladkey@knute.edu.ua }}$
} 
Extreme situations, along with the natural disasters, can also create environmental and technological disasters, economic crises, social stress, crime, regional conflicts $[1 ; 2 ; 3 ; 4$; 5]. The above phenomena fit under the main features of the extremality: have high-speed implementation; marked with a permanent development of a dynamic social chaos, where individual elements of the social system do not correspond adequately; form an unbalanced potential instability. From a private and barely visible case, they gradually turn into a prolonged continuous process [6], a kind of extreme mode of systems functioning (landscapes) and an essential component of their existence.

\section{Results}

The use of a systematic approach and consideration of geographical systems (landscapes) as complex dynamic socio-ecological-economic systems make it possible to distinguish, respectively, three groups of destructive factors - sociogenic, naturegenic and technogenic. Their separate or interrelated influence on the landscape leads to the emergence of extreme situations of a various nature and an increase in the instability of the system as a whole (Fig. 1.)

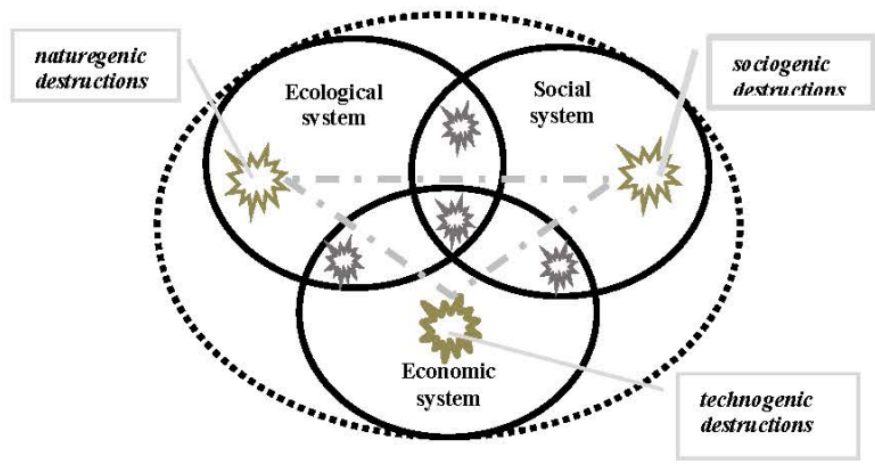

Fig. 1. Destructive factors in the model of the socio-ecological-economic system.

The stability of the system rests on its diversity. For example, with the increasing complexity of the technosphere, its diversity is simplifying and risks of a catastrophic outcome are increasing. In this respect, modern civilization is very unstable. All the civilization, for example, hung on electricity.

Classics of geography clearly realized that with the complication of civilization, its dependence on nature is growing. A.A. Kruber wrote: "Of course, a wild man is more under the yoke of nature than a man of culture.... But the dependence of the latter on the environment did not diminish, it only became more diverse. The well-being of a modern farmer depends on the size of the crop, that is, the weather conditions and the fertility of the soil, and on the degree of soil cultivation, and on the bread prices in the market, i.e. from the harvest of other, often very remote countries, and from the conditions for the supply of agricultural products to railroad stations, from many other causes» [7, p. 202-203].

Over the past 40 years of the 20th century, the number of natural disasters on the globe has increased threefold. The economic damage from them increased 9 times during the same period [8]. According to the forecasts of a number of researchers [9-12], provided that current trends continue, the humanity by the middle of the current 21 st century waiting for 
a full collapse- it will have to work only to repair the damage from disasters. Geographical studies also convince the great role of natural disasters in the deaths of cities and civilizations $[13 ; 14]$. In the social aspect, they cause the development of dynamic public chaos, form the potential for unstable development of the territory, violate the social identity of the individual and lead to the irrationalization of social consciousness [15]. They are interrelated and have common tendencies of territorial localization, development, expansion and functioning [16].

The popularity of opinion about extreme processes and phenomena in geography requires a more precise justification for the notion of «extremality», the definition of its components and comparison with general scientific concepts. There was an idea in geography and landscape science, for a period of time, about extreme areas of human life. These included, in fact, the territories or areas within which unfavorable conditions of human life existed, representing threat to his health and efficient economic activity [17]. Examples of such landscapes are the regions of the Far North of Russia with a severe and harsh climate, as well as territories affected by environmental pollution.

In geography this approach was applied only to determine the specific features of the influence of natural conditions on human activity. It did not cover those destructive processes and phenomena that were associated with the life activity of society (decline in the quality of human capital, the growth of crime, poverty, the spread of drug addiction, alcoholism, acts of civil disobedience, etc.). It means, it did not have a socio-derived determinism. Extremism of geographical systems (landscapes) is more expedient to consider as a combination of various tense, non-stationary, unbalanced factors, concluded both in the features of the environment, and in the characteristic features of the life of society, which derive the social and economic systems from the state of stability.

However, the consideration of only a few particular processes and phenomena of social ill-being will not give an answer to the whole complex of issues related to the instability of a certain geographic system (landscape). The fact is that social systems develop in direct interaction with natural and economic systems. Therefore, it is impossible to single out a separate group of extreme processes and phenomena, without taking into account the influence of others. In our opinion, extreme events are not limited only by the instability of social systems, but also take into account the natural, environmental, technical and technological factors for the safe development of landscapes. Thus, the geography of extreme situations is designed to explore those destructive and destabilizing processes and phenomena in the life activity of nature and society that derive geographic systems (landscapes) from the state of stability (sustainable development) and contribute to the disturbances and changes in their system-structural state, their withdrawal to the unbalanced mode of operation.

For some generalization, we give the scheme for the extreme development of the territory (behind Anderson), where the sequence of stable and extreme (unstable) state of the landscape is reflected [17]. The periods of stability and instability (extremality) alternate, changing each other. The period of stability is the time of the productive development of geographic systems (landscapes), in which all components of the territory are interrelated and function as a single whole. This stage ensures sustainable development of the landscape, the fullest use of its capabilities, a continuous improvement in people's livelihoods, environmental management, and so on. In periods of instability, the balance disappears- and the population, economy, natural resources and other components of geographic systems lose mutual coherence of development, tightness of interconnection, unity and proportionality of management. There is a choice between alternatives for further development. Depending on the intensity of the crisis processes and the effectiveness of counteraction measures, the territory can receive both upward and downward trends of 
further development. This «dynamic extremality» is natural and manifests itself in all natural and social conditions, but with varying intensity and consequences.

For a complex definition of the main destructive processes and phenomena that disturb the balance and proportionality of the functioning and development of geographic systems (landscapes), a system of ball score of the level of the territory extremality is effective. This method is based on the systematization of statistical data (the level of crime and social stress, environmental pollution and man-made disasters), translating them into relative indicators and revealing the cumulative impact of all extreme phenomena on the processes of landscape existence. To assess the level of crime, it is more appropriate to use relative indicators, namely the crime rate within a certain territory. When assessing social stresses, the most complex indicator is the number of participants in civil disobedience acts. It is also possible to use indirect indexes characterizing the phenomenon: the number of orphanages and homeless shelters, the number of unemployed and persons without a fixed place of residence and occupation, the number of divorces, the percentage of juvenile delinquency, the number of suicides on socio-economic grounds, etc.

The extremeness concept of control and monitoring of the territory is based on general theoretical fundamentals of the socio-geographical science and, therefore, in methodological aspect it rests on the following principles [18].

Principle of integrity of extremal-geographical processes and phenomena investigations at various hierarchical levels. The extremal phenomena are characterized by integrity of destructive influence on the stable development of society. Therefore, comprehensive consideration of the peculiarities of their formation and functioning, study of their structure, internal and external interrelations, of complex character of their manifestation and development of well-coordinated measures of counteraction can provide possibilities for predicting, preventing and controlling these processes on the territory.

Realization of this principle requires a combination of common sciences and special methods and techniques, an effective mechanism of their practical use.

The principle of regionalism provides for creation of rational territorial regular order of all components of socio-geographical complexes, which form socio-geographical space. Such formation is possible only on condition that the territory's extremal potential decreases, the lost equilibrium is re-established, the stable development of society and the systems of natural resources use is provided. Regionalization is an effective method of determining the level of extremeness of particular territories and the structure of their extremal potential. A practical implementation of this method is an essential component of society's territorial organization, optimization and the development of particularly addressed programs for stabilizing society's vital activity.

Principle of complex character and proportional development of society. This principle means that society is a counterbalanced system, which functions as an unified complex, where all interrelated components cannot exist separately. Hence, society's development has to involve all above-mentioned components on the specific territories in common systematic processes (complex development) with optimal and counterbalanced coexistence of all elements in a socio-geographical system (proportional development). Extremal processes and phenomena lead to equilibrium disturbance. As a result, complex and proportional development becomes unreal.

Principle of conservancy, according to which society creates for itself optimal systems of natural-resources potential use and steadily improves environmental conditions.

Principle of permanent improvement of social welfare. According to this principle, the human needs, rights, interests, possibilities and requirements are in the center of the functioning of socio-geographical complexes. So, all scientific programs must be aimed at the observance and improvement of these conditions. 
Principle of historical approach. According to this principle, all extremal phenomena and processes are considered in dynamics for revealing the reasons of their creation, sequence and phases of development.

Principle of predicting. It helps to determine a trajectory of development and future conditions of propagation of extremeness on the territory. The most frequently used approaches are: linear and non-linear predicting, expert estimations, foresight, method of analogy and modeling, numerical score.

Principle of mapping of extremal-geographical processes and phenomena. The extremal phenomena have spatial and temporal distribution, so one can show them on the map.

The indicators of environmental disasters can include the amount of pollutant emissions into the atmosphere, the discharge of contaminated sewage into the natural surface water, the degradation of soil resources, the reduction of the forest fund, the species diversity of flora and fauna. Man-made disaster can be determined by the number of cases of accidental pollution of the environment, the number of accidents and abnormal situations at industrial production facilities and transport.

The practical effect of the considered principles can be demonstrated by the following examples. So, the beginning of the 21 st century was marked by the further increase of the civilization dependence on force of nature and the areas they covered. Apparently, the first $2 / 3$ of the 20th century was distinguished by an ideal geological and climatic stability. Most of the major technologies of our time have been built to this stability.

The eruption of Island Mountain Glacier (Eyjafjallajökull volcano) in 2010 in Iceland carried ash to a height of $13 \mathrm{~km}$, which was hanging there for 2 weeks. This event significantly affected the work of jet aviation. The eruption of the Krakatau volcano in 1883 threw ash at a height of $80 \mathrm{~km}$, which was staying in the atmosphere for 3 years [19]. If such an event occurred in our days, we would have to part with the jet aircraft.

The eruption of Island Mountain Glacier (Eyjafjallajökull volcano) in 2010 caused a crack length of $500 \mathrm{~m}$. In addition, the eruption of another Icelandic volcano Lucky in 1783-1784 caused a crack length of $25 \mathrm{~km}$, erupting for 7 months. A mixture of ash, sand, fluorine and sulfur compounds that fell with acid rains destroyed almost the entire grass cover of Iceland. $80 \%$ of Icelandic sheep, $50 \%$ of cattle and horses died from lack of grass. As a result, 100000 people, i.e. a quarter of the total population of Iceland, died of starvation and fluoride pollution. The life of the Icelandic nation was endangered.

On the other hand, if the earthquake of March 11, 2011, which destroyed the Fukushima nuclear power plant, would have happened 100 years ago, then the consequences for Japan would have been less. Residents of seismically active islands lived in light-framed folded houses. The Russian writer Boris Pilnyak, who visited Japan in the 1920s, noted: «The whole Japanese life rests on earthquakes. These earthquakes freed the Japanese people from dependence on the thing and removed the thing» [20]. Today, this way of life of the Japanese has become a thing of the past. Modern Japan has become a symbol of unrestrained consumption. Complication of everyday life entails an incredible increase in the number of victims in various kinds of catastrophes.

One can argue that the similar in strength Tokyo earthquake of September 1, 1923 caused an even greater number of victims. Then 174 thousand people died and 542 thousand were missing. But the epicenter of the earthquake in 1923 was only $80 \mathrm{~km}$ from Tokyo and $65 \mathrm{~km}$ from Yokohama, near the most populated bay of Japan. The epicenter of the most powerful earthquake of 2011 was far enough in the ocean, $130 \mathrm{~km}$ from the nearest town of Sendai. Today such an earthquake, as in 1923, would have much more serious consequences.

Icy rain at the end of 2010, too, would not have left 100 years ago the inhabitants of the Moscow region villages for 2 weeks without light and heat, as people were heated by coal and wood. The trains would not stop, as they were carried by locomotives. 
The strongest of all ever instrumentally recorded solar storms, which caused a powerful release of plasma, occurred in 1859. It was well studied and was called the «Carrington event», after the name of astronomer Richard Carrington, who described it. This little event, then extrapolated to our days, would, in all respects, cause a real global catastrophe.

A powerful electromagnetic pulse would burn computers, televisions, household appliances, electrical substations. Moreover, the more powerful the substation, the greater its grounding and the stronger the destruction. Disabled satellites, power grids, electronicswitching systems would paralyze the work of entire continents. All the new cars full of electronics would stop. People would have to buy old Lada, which immediately would increase in price incredibly.

The geomagnetic storm of 1859 in our days would destroy all electronic payment systems. It turns out, that electronic money is much less stable than paper banknotes, as those in turn are also exposed to risks compared to gold and precious stones that went before they were consumed.

The cause of the accident at the nuclear power plant «Fukushima», oddly enough, was not the element itself. The accident itself was caused by the power outage. As a result, pumps that had to constantly cool the reactors stopped working. Went to diesel generators. They also went off, but after the main element. Nuclear fuel continued to generate a huge amount of heat and radioactive vapor. To prevent a nuclear explosion, it was necessary to build a new power line of $7 \mathrm{~km}$ length. This power line was constructing during two weeks. Pumps, generators, power lines, the impression that we are talking about some collective farm, and not a country of «hi-tech». An earthquake in the ocean near Japan showed that nuclear power plants, which, as we are told, are capable of withstanding an atomic strike, do not withstand the usual blackouts.

Tsunami in 2011 in Japan caused an earthquake, which led to the formation of a ledge length of about $500 \mathrm{~km}$ with an amplitude of displacement of $10 \mathrm{~m}$ [U.S. Geological Survey]. As a result, 10-meter waves went $5 \mathrm{~km}$ deep into the country, sweeping everything in its path. The cause of the tsunami on December 26, 2004 on the Andaman coast was a 16 $\mathrm{km}$ long fault. One of the sides of the ocean floor rose along the fault by $20 \mathrm{~m}$. This movement caused waves that killed 250 thousand lives.

If such insignificant cracks in the earth's crust or the movements of the ocean floor cause such devastating events, then what splashes of waves should be accompanied by past discharges and dips of large areas of the ocean floor by several hundred meters, maybe even kilometers? In the coastal plains, similar events were to occur, in the words of N.F. Zhirov [21], «super-tsunami» with a height of «megawaves» of hundreds of meters.

A catastrophic picture of the planet's history is becoming clearer. Impartial witness can see it everywhere- in giant folds and strata of rocks, in cliffs and quarries, in moraine boulders, in deposits of fossils of giant extinctions. It is extremely important to understand the power of even more grandiose elements. The reinterpretation of geological evidence along the lines of a non-catastrophic model can serve as a new, more accurately «wellforgotten old», a compass not only of practical, but also of scientific and philosophical search.

Any major catastrophe, like the eruption of Island Mountain Glacier (Eyjafjallajökull volcano) in April 2010, visually closes physical geography with the geography of the economic and at the same time turns out to be beyond the close examination of both. A special topic of science should be recognized those threats that could already threaten humanity, and those that could destabilize it in the future. With the increasing complexity of the technosphere, there is a simplification of its diversity and the risk of a catastrophic outcome.

Paradoxically, however, that is why it is important to preserve obsolete technologies and archaic ones such as locomotives, carburetor cars, biplanes or sled horses and the 
accompanying work skills. In a critical regime, it is difficult to overestimate them. Tourism can save them today. If history is not presented as a tourist product, it is forgotten. The uniqueness of tourism lies in the fact that in the study of the functioning and foresighting of the extreme situations in its development, a model of the socio-ecological-economic system can also be used with the allocation of a group of sociogenic, naturegenic and technogenic factors [22, 23].

There are many works that describe the threats tourism brings to natural and cultural heritage sites. Much less attention is paid to the fact that these sites exist primarily due to tourism. Venice would not have survived without tourism and «museumization». Nature is not an exception too. The system of specially protected natural territories (reserves, national parks, reserved forests) simply will not survive without the constant interest of the population, carried out by tourism.

As noted above, the concept of extremeness can reflect a state whose qualitative characteristics are caused by the natural and/or anthropogenic reasons. Therefore, this concept should concern not only natural indices of the state of environment which influence the human vital activity, but also the indices of functioning of various socio-ecologicaleconomic systems. The standard indices and deviations from them can be expressed in partial indices - demographic (morbidity, birth and death rates, etc.), environmental (climatic, hydrological) and also in economic and social indices (index of sustainable economic welfare and human development index). However, quantitative indices (amount of financial support for protection of environmental and social systems) are more convenient for determining extremal conditions.

To reveal extremal regions on specific territories (a group of countries, a single state or its regions), one can use a variety of methods and methodological approaches. The common methods of investigating extremal-geographical processes and phenomena have been a systematic approach, structural analysis and synthesis, socio-geographical modeling, statistical method, generalization, etc.

Among methods of extremeness level evaluation in particular regions one can mark off the method of statistical data systematization with the subsequent co-ordination of empirical data and territorial units as well as the method of numerical score.

All components of extremal systems (crime, ecological, technogenous and social catastrophes) are distinguished by their interconnection and function as an integrated destructive phenomenon or an "antisystem". That is why consideration of their solitary influence on the development of regions is unable to reconstruct holistic information on the actual state of territories. Therefore, the administrative solutions and methods of getting out of a crisis will be ineffective. The extremal phenomena should be investigated in their unity and aggregate of manifestation.

Such an integrated system of distribution of extreme-geographical processes and phenomena on a territory can be revealed by mapping. In evaluating the extremal aspects of the territory development of particular regions in Ukraine, a combined mapping model has been used which shows the degree of manifestation and the interrelation of separate extremal components.

The circular charts on the map show the crime rate, ecological and technogenous accidents and social stresses. The method of quantitative background shows the structure of population settlement in selected regions.

For creation of the circular charts the indices of their components were ranked by the method of numerical score. For evaluation of crime rate in the regions the index of the quantity of registered crimes on a particular territory was used.

In evaluation of social stresses, the most comprehensive index, in our opinion, is the number of people taking part in strikes and public disorders. It is this index that was taken as the basis for creation of the map. Also, it is expedient to use the following indices: the 
rate of unemployment and incomplete employment; the part of the poor people; the part of incomplete families; the number of shelters for orphans, invalids and the homeless; percentage of divorces in total quantity of marriages, etc.

The indices of ecological accidents in Ukraine include the number of emissions of pollutants into the atmosphere and discharge of polluted waters into natural surface water basins. It is also expedient to use the data on the level of pollution of both land resources and underground waters. The combination of these indices will make the description of the ecological situation more comprehensive and reliable.

Technogenous accidents have been estimated using the quantity of environment pollution accidents. It is this index that allows determining a degree of influence of technosphere on the vital activity of nature and society.

The obtained results suggest dominance of extremal processes and phenomena in densely populated and highly industrially developed areas. The greatest extremal potential in Ukraine is in eastern regions (Donetsk, Dnipropetrovsk, Kharkiv, Lugansk and Zaporizhzhia regions). In the structure of their potential the basic part belongs to ecological accidents, crime rate and social crises. This is ascribed to a high level of urbanization and industrial development, high communicability of environment, dominance of heavy and mineral industry, insufficient development of industrial and social.

In the mentioned regions, technogenous accidents of medium intensity in industry and transport are observed as well. However, the consequences of these accidents are insignificant. It is due to creation of an effective system of cleaning and recycling, use of novel technologies as well as a high level of personnel qualification on this territory.

The regions of medium development (Odesa, L'viv, Poltava, Ivano-Frankivsk regions) have a lower degree of propagation and distribution of extremal processes and phenomena. These regions are also characterized by large indices of crime and social stresses. However, the ecological pollution of the territory is decreased. Therewith, in all regions the high level of technogenous pollution of environment due to accidents is detected.

These regions have rather low indices of industrial modernization. That is why the number of unexpected accidents and their consequences increase considerably. Unsufficient financial support of preventive measures in the industrial sector and a low level of infrastructure service also influence the growth of environmental pollution due to accidents.

The low indices of extremal processes and phenomena are characteristic of the regions where predominate agricultural production, are low both urbanization level and the density of population (Ternopil, Vinnitsa, Chernihiv, Zhytomyr and other regions). Developed in these regions are the processing industries. Technogenous accidents predominate in the structure of extremal potential. The reasons were considered above. The number of social stresses and crime rate are insignificant. As compared with the highly developed regions, the ecological situation approaches the standards.

Separately described should be the situation in the metropolitan region of Ukraine. The Kyiv region is noted for a rather low level of extremeness. The crime rate and pollution of environment are permanent on this territory. The indices of social stresses and technogenous accidents are very low. In this situation the influence of capital is traced. As any large agglomeration, Kyiv has high indices of crime and pollution. The low level of social stresses is caused by relatively better population living conditions, high level of providing the material possessions and nonmaterial benefits.

Extremal indices can be compared with the help of mapping models. The latter allow one to draw certain conclusions about the features of functioning and development of regions. The efforts of administration should be directed to overcoming the negative tendencies in development of above-mentioned territories with taking into consideration the structure and relations between extremal components. 
Criminality, accidents (natural, ecological, technogeneous and social), and also conflicts are original social phenomena, which completely fall under basic features of unstable extremal systems. Their genesis, distribution, development and operation are the reason of formation of extremal - geographical elements in space and time - extremal processes and phenomena. They depend in own development from socio-geographical realities, level of assimilation of territory and development of society in economic, technological, social aspects, from systems of natural use, control and self-organizing systems. The stable position of socio-ecological-economic system junction with unstable, therefore there is become new public formation or parameter's modification of existing system, new regime of its existen.

\section{Conclusions}

The researches which have been carried out on Ukraine's territory, allow to affirm, that the level of development of conflict situations, social accidents and criminality in separate regions of the country is territorially localized in places of the greatest amount of technogeneous and ecological accidents, greatest urbanization and concentration of population. That is, we can make such conclusion, that those extremal processes and phenomena are interconnected in space and time. They depend of amount of the population in region, in particular of urban population, depends of density of settlements, level of a changing and pollution of environments, engineering upkeep, skill to communicate and technocratization. They are located on the same territories and exert complex influence on them.

Thus, the concept of «extremality» can reflect such a destructive state of it, the qualitative characteristics of which are caused by either natural and anthropogenic causes, or a combination of both types of causes. Parameters of norms and deviations can be expressed in partial indices- medical and demographic (morbidity, birth rate, mortality, etc.), socioeconomic (rising crime and unemployment, lowering the level of economic development, spreading poverty), engineering (damage rate of equipment and vehicles, worn-out state of fixed assets), physical-geographical (climatic, hydrological, ecological). The development of the geography of extreme situations and survival strategies in them is becoming a new imperative of geographic science.

The proposed approach for evaluation of extremal potential in regions can be used not only on the territory of Ukraine, but also in the countries of the European Union, in other regions of the world. The distribution of extremal-geographical processes and phenomena has similar objective laws of development in various economic, social and political conditions. They can only differ in various intensity and proportionality. Therefore, these methods of evaluation of unstable aspects in vital activity of society (in view of national features) can be used for investigations of other territories.

\section{References}

1. E. M. Babosov, Catastrophes: the sociological analysis, (Minsk, 1995)

2. S. I. Ishuk, H. P. Ishuk, O. V. Hladkyi, Extreme geography: the essence, structure, situation in Ukraine Ekonomichna ta sotsialna heohrafiia 48, 18-30, (1999)

3. L. G. Serebrjanyj, A. Ju Skopin, Supported, balanced or sustainable development, no. 1, (1998), pp. 44-49,

4. E. Biagini, Spatial dimensions of conflict. 27th International Geographical Congress. Washington. August 9-14, (Washington DC, 1992)

5. D. Harvey, Social Justice and the City, (1996)

6. O. I. Shabliy, Socio-economic geography of Ukraine, (Svit, 1995) 
7. A. A. Kruber, General geography, Vol III. Biologia i antropogeografija, (1922)

8. V. I. Osipov, Natural catastrophes at the turn of the XXI century 71, 291-302 (2001)

9. A.V. Vikulin, N.V. Semenec, M.A. Vikulina, Geodynamics-society and the biosphere through the eyes of catastrophes, Biokosmologija - neoaristotelizm 2, 165-181 (2012)

10. M. Koval'chuk, O. Narajkin, Designer for the future, V mire nauki 9, 24-31 (2011)

11. S. M. Mjagkov, Geography of natural risk, (Izd-vo MGU, 1995)

12. D. Forrester, World Dynamics, (Izd-vo AST, 2003)

13. Al. A. Grigor'ev, Ecological lessons of the historical past, (1991)

14. L. Grigor'ev K., Ja. Kondrat'ev, Ecological disasters, (Institut jekologicheskoj bezopasnosti RAN, 2001)

15. D. Harvey, Social Justice and the City, (1996)

16. L. C. Gordon, P. F. Maryann, S. G. Meric, The Oxford Handbook of Economic Geography, (2002)

17. E. Biagini, Spatial dimensions of conflict, 27th International Geographical Congress. Washington. August 9-14, (Washington DC, 1992)

18. M. D. Pistun, The basis of the theory of social geography, Vyscha shkola (1996)

19. I. I. Gushhenko, Eruptions of volcanoes of the world: Catalog, (1979)

20. N. A. Ionina, M. N. Kubeev, 100 Great Catastrophes, Veche (1999)

21. N. F. Zhirov, Atlantis, Geografgiz, (1957)

22. T. I. Tkachenko, Stalyi rozvytok turyzmu: teoriia, metodolohiia, realii biznesu (Sustainable tourism development: theory, methodology, business realities), (Kyiv National University of Trade and Economics, Kyiv, 2006)

23. V. Bilyk, V. Romanyshyn, V. Krush, Tourism futurology as a research area in tourismology, (2020). 